\title{
Of Blades and Branches: Understanding and Expanding the Arabidopsis Ad/Abaxial Regulatory Network through Target Gene Identification
}

\author{
T. Liu, ${ }^{1}$ B.J. Reinhart, ${ }^{1}$ E. Magnani, ${ }^{1}$ T. Huang, ${ }^{2}$ R. Kerstetter, ${ }^{2}$ and M.K. Barton ${ }^{1}$ \\ ${ }^{1}$ Department of Plant Biology, Carnegie Institution for Science, Washington, D.C. 20005 \\ ${ }^{2}$ Waksman Institute, Rutgers The State University of New Jersey \\ Correspondence: kbarton@stanford.edu
}

\begin{abstract}
HD-ZIPIII and KANADI transcription factors have opposing and dramatic affects on plant development. Analysis of mutants shows these proteins to be master regulators of ad/abaxial (i.e., upper/lower) leaf polarity, leaf blade outgrowth, and branch formation. Because these factors do their work by regulating other genes, we have focused our attention on defining their targets. We have found overlap between the ad/abaxial regulatory pathway and hormone signaling pathways, especially pathways of abscisic acid and auxin signaling. This has led to the discovery that abscisic acid signaling acts upstream of HD-ZIPIII and KANADI in the control of germination and may ultimately explain how environmental stress pathways control new growth at the shoot apex. Auxin signaling conversely is downstream from HD-ZIPIII and KANADI action with these factors controlling targets at all steps of auxin action — biosynthesis, transport, regulation of transport, and signaling. Based on these findings, we propose a model in which the HD-ZIPIII and KANADI factors pattern auxin response in the embryo. Finally, many genes targeted for control by HD-ZIPIII and KANADI proteins are themselves transcription factors - indicating these master regulators call up tissue specific subprograms of transcriptional control to affect the many polar differences observed across tissues.
\end{abstract}

Leaves are typically thin, flat organs specialized for harvesting light energy from the sun. Using this energy, in what must have seemed to early scientists like a feat startlingly close to alchemy, leaves turn carbon dioxide and water into sugar and oxygen. The flattened nature of the leaf, which maximizes surface area both for light capture and for gas exchange, exists in tension with the need to prevent excessive water loss, especially in dry environments. Thus, the size and shape of the leaf blade varies greatly among species and with the diverse habitats found on land. Plants growing in dry environments often make narrow leaves with limited surface area that are sufficient to support the slow growth allowed when water is limiting. On the other hand, plants growing in moist, nutrient-rich environments may make large, tender leaves the better to compete with their neighbors for light and space. Leaf shape may even vary substantially during the lifespan of an individual plant, especially when the environment changes substantially during this time. Extreme examples of this are aquatic plants in which the early leaves formed under water have very different shapes from the later leaves formed above water.

We have been studying the mechanism of action of regulators of ad/abaxial leaf polarity in the plant. Besides directing different patterns of cellular differentiation in the upper and lower halves of the leaf, these regulators also control blade outgrowth and the formation of new branches. Owing to their ability to influence such basic growth properties, the ad/abaxial regulators are expected to be perfectly suited targets of evolutionary modifications that allow plants to survive in many environments. Their activity may also be affected by physiological signals reporting on environmental change occurring during the course of the lifetime of a single plant. As these regulators are transcription factors, the key to understanding how they work must rest, at least in part, in an understanding of what genes they control. Our approach has been to identify, with as much confidence as possible, the genes controlled by the ad/abaxial regulators and to use this information to identify new actors required for leaf development and to test new hypotheses. In this paper, we summarize the discoveries and the hypotheses that have emerged from these studies.

\section{THE ORGANIZATION OF THE LEAF}

The upper, or adaxial, and lower, or abaxial, domains of the leaf are functionally specialized - the upper portion is specialized for light capture whereas the lower portion is specialized for gas exchange. In the mesophyll of a typical dicotyledonous leaf, the upper portion of the leaf possesses tightly packed, chloroplast rich cells to allow for efficient light capture. In some cases these cells are arranged as densely packed dominos with their short ends facing the surface into a palisade layer (Fig. 1A). This arrangement has been suggested to allow the cells to act as light pipes to more efficiently bring light into the leaf. The lower 
A

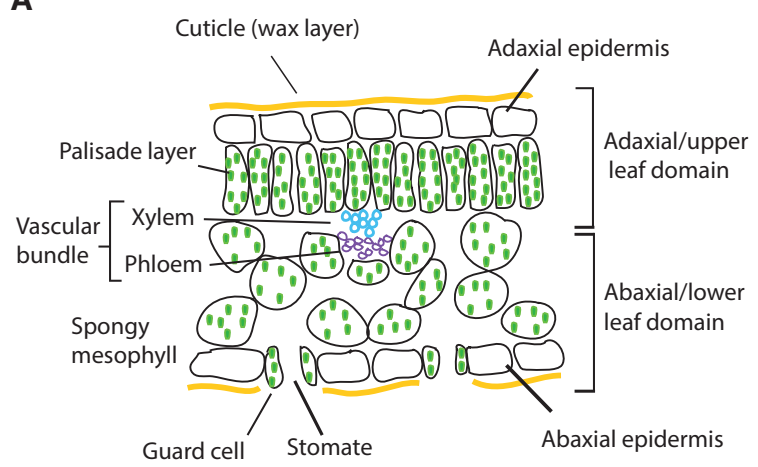

B

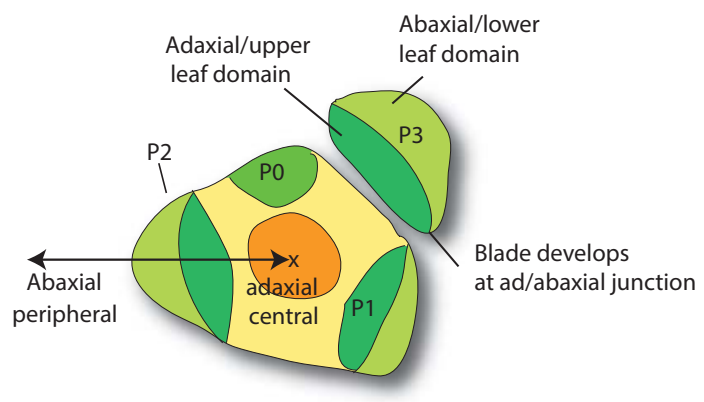

Figure 1. Ad/abaxial organization of a mature leaf and of young leaf primordia developing from a shoot apical meristem. $(A)$ Schematic of cross section through a typical leaf. The leaf is bounded by the epidermis. Cells of the epidermis secrete waxes that form a water impermeable cuticle over the plant. Stomates are pores through which water vapor, oxygen, and carbon dioxide can easily diffuse. Stomates may be present at higher density on the lower surface of the leaf relative to the upper surface of the leaf as a mechanism to prevent dessication. Hair cells or trichomes (not shown here) are also often found as specialized cells of the epidermis. Trichomes may help to reduce desiccation by slowing air flow across the surface of the leaf or they may produce toxic substances to protect the plant against predators. The inside of the leaf includes chloroplast rich mesophyll cells and vascular cells. In the upper, or adaxial, domain of the leaf the mesophyll cells may be elongate and densely packed in a layer of palisade cells to allow for efficient light capture. In the lower or abaxial domain, cells of the spongy mesophyll are loosely packed to allow for efficient gas exchange. Vascular cells are typically organized with xylem (water-carrying) cells, located adaxial to phloem (photosynthate transporting) cells. (B) Schematic of a shoot apical meristem showing the spatial organization of newly formed leaves. Stem cells are located in the central zone (orange). As they divide, their descendants are pushed outward into the peripheral zone where they participate in the formation of leaf primordia. Leaf primordia are labeled P0, P1, etc. in order of age (P0 is the most recently formed). Leaves acquire ad/abaxial polarity while they are closely associated with the shoot apical meristem. The portion of the leaf primordium closest to the central long axis of the plant (x) develops as the adaxial domain. As the leaf develops, the adaxial domain grows faster than the abaxial domain causing the leaf to bend away from the plant with the adaxial domain facing upward. The leaf blade grows out at the junction between ad- and abaxial domains.

portion of the leaf, in contrast, typically consists of loosely packed cells that facilitate gas exchange between the plant and the environment. Surface characteristics may also distinguish the upper epidermis from the lower epidermis. For instance, the upper epidermis may secrete a thicker wax layer (cuticle) and may have a lower density of stomates to prevent desiccation. Trichomes, "leaf hairs," of various types and densities, may also distinguish the upper epidermis from the lower epidermis. Cells within the vascular bundles typically show a distinct polar arrangement with water-bearing xylem cells located adaxial to the underlying sugar transporting phloem cells (Fig. 1A).

The upper and lower portions of the leaf become distinguishable when the young leaf primordium is closely associated with the shoot apical meristem. (Fig. 1B). The future upper portion of the leaf is closer to the center of the plant, whereas the future lower portion is further from the center of the plant. For this reason these regions are referred to as adaxial (from the latin "ad-", meaning "toward" the long axis of the plant) and abaxial ("ab-" meaning "away from" the long axis of the plant). As the leaf develops, the upper domain of the leaf grows more than the lower domain causing the leaf to bend away from the plant - the adaxial domain thus becomes the upper portion of the leaf and the abaxial domain becomes the lower portion. (If you are likely to forget your Latin roots, it may be easier to remember that the abaxial side of the primordium will become the bottom of the leaf whereas the adaxial side will become the "dop" of the leaf.)

Zooming out to consider the leaf primordium in the context of the entire shoot apical meristem, the ad- and abaxial positions within the developing leaf primordium can be viewed as points along a line extending from the center of the plant outward (Fig. 1B). Positions along this line include the central zone-home of the self-renewing stem cells of the shoot apical meristem - and the peripheral zone, the zone in which new leaf primordia form. The ad- and abaxial domains of the young leaf primordia may then be considered to be subdomains of the peripheral zone.

Zooming out even more to consider the shoot apex in the context of the entire plant, positions along this central-peripheral ad-peripheral ab line, are a set of shoot specific coordinates of what are more generally called positions along the radial axis. This is very clear in the embryo where the domain that includes the adaxial cotyledon domains is continuous with the inner vascular cylinder (Fig. 2A,B), whereas the abaxial cotyledon domains are continuous with the outer cortical and epidermal layers of the hypocotyl. The criterion for calling these domains is based on domains of gene expression - for instance, the adaxial domain accumulates HD-ZIPIII mRNA (McConnell et al. 2001; Fig. 2C,D).

\section{THE IMPORTANCE OF THE AD/ABAXIAL BOUNDARY TO LEAF BLADE DEVELOPMENT}

In the embryo, the formation of distinct adaxial/abaxial domains of the cotyledons (or seed leaves) is detectable in the globular embryo before cotyledon outgrowth occurs (McConnell et al. 2001). Roughly equal rates of growth of the ad- and abaxial cotyledon domains cause the embryo 

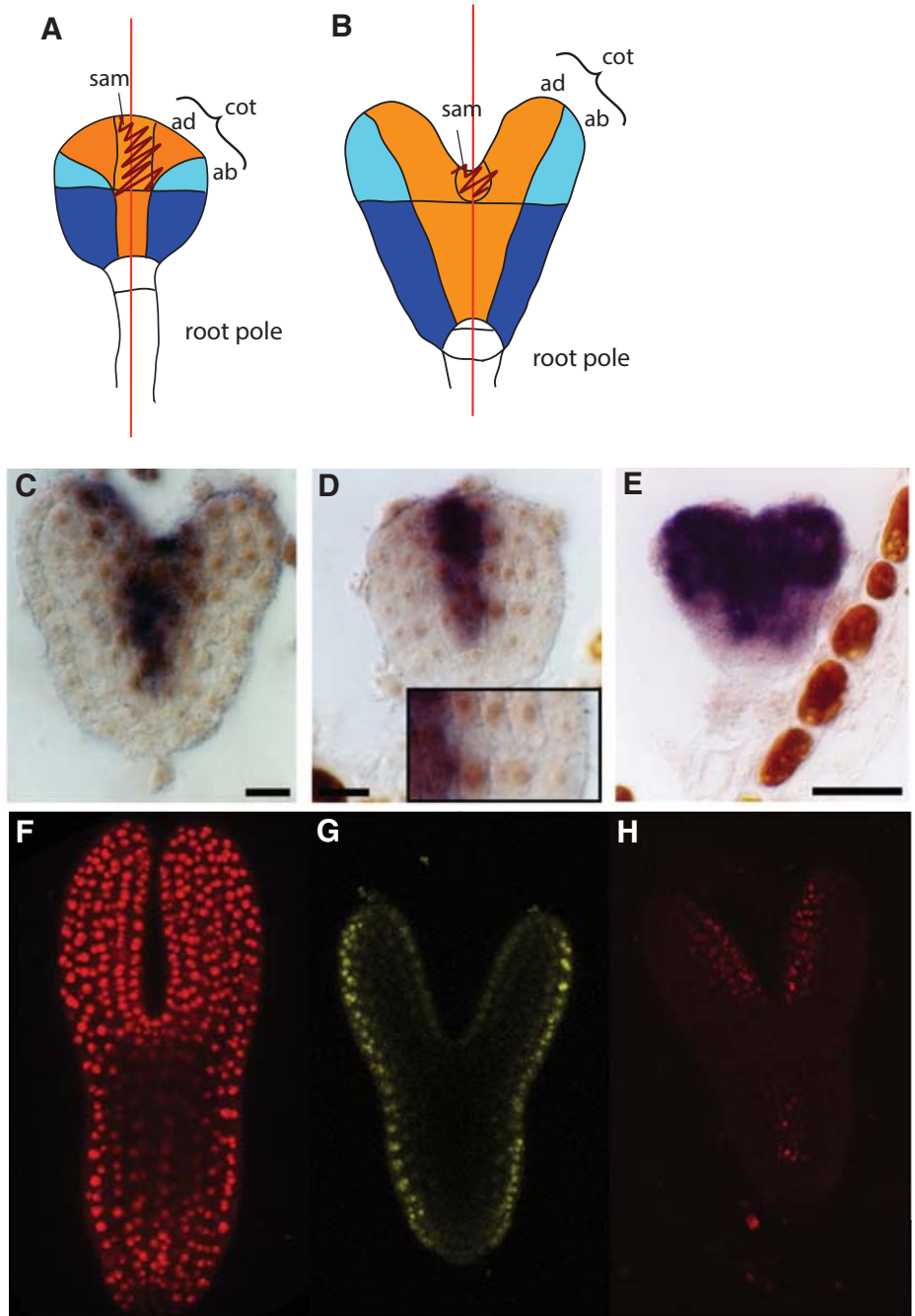

\section{H}

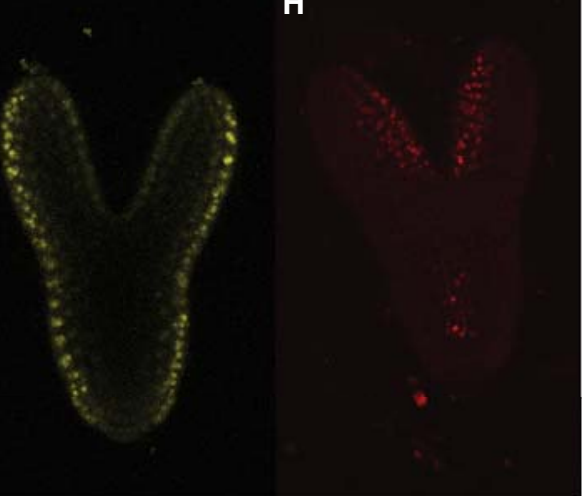

Figure 2. Ad/abaxial development in the Arabidopsis embryo. (A) Globular embryo. (B) Heart stage embryo. (C) Accumulation of HD-ZIPIII (PHABULOSA) transcript in wild-type heart stage embryo viewed in frontal section. $(D)$ Accumulation of HD-ZIPIII (PHABULOSA) transcript in wild-type heart stage embryo viewed in sagittal section (rotated 90 degrees relative to C). Note gradient of mRNA accumulation. (E) Ectopic accumulation of microRNA resistant PHABULOSA transcript in phb- $l d$ mutant embryo. $(F)$ Expression of a PHB-promoter-YFP construct lacking a microRNA complementary site (MCS). Expression is throughout the embryo. $(G)$ Expression of mir165-YFP reporter. Note that signal is highest in the abaxial, or peripheral, epidermis. $(H)$ Expression of a PHB-promoter-YFP fusion that includes an MCS. Expression is limited to the most adaxial, or most central, cells of the embryo. (sam) - Shoot apical meristem; (cot) Cotyledon; (ad-adaxial domain) orange; (ab-abaxial domain) light and dark blue; (red squiggly line)-region expressing KNOX shoot apical meristem marker.

to adopt a heart shape (Fig. 2B). Subsequently, the abaxial domain grows faster than the adaxial domain causing the cotyledons to rotate inward and the embryo to adopt a torpedo shape (Fig. 2F).

A critical insight into the importance of the ad/abaxial boundary to leaf blade development was made by Waites and Hudson (1995). They observed leaves of mutant snapdragon plants in which patches of abaxial leaf tissue were surrounded by adaxial leaf tissue. Ectopic flaps of leaf blade developed at the boundaries of these patches. This, together with the observation that abaxialized mutant snapdragons made narrow bladeless leaves, led Waites and Hudson to propose that juxtaposition of adand abaxial boundaries was necessary and sufficient for the placement and outgrowth of the leaf blade. Evans
(2007) observed similar sectors in maize leaves indicating that this is a general mechanism of blade development conserved in monocots and dicots. McConnell and Barton (1998) showed that adaxialized Arabidopsis mutants similarly made bladeless leaves but with adaxial characters around their circumference, providing further support for the generality of the model.

For the plant to make flat leaves, growth rates must be coordinated between the ad- and abaxial sides of the leaf. Plants carrying mutations that cause adaxialization show upward leaf curling, indicating that the bottom half of the leaf grows more than the top half (McConnell et al. 2001; Ochando et al. 2006; T. Huang et al., unpubl.). Plants carrying mutations that cause abaxialization show downward leaf curling, indicating that the top half of the leaf 
grows more than the bottom half (Talbert et al. 1995; Wenkel et al. 2007).

\section{HD-ZIPIII AND KANADI PROTEINS ACT OPPOSITELY TO CONTROL LEAF POLARITY}

A small handful of genes to date are known to control the development of ad/abaxial polarity in the leaf (reviewed by Husbands et al. 2009). Genes required for adaxial leaf development are three of the five $H D$-ZIPIII genes (REVOLUTA, PHABULOSA, and PHAVOLUTA) and the $A S Y M M E T R I C 2$ gene. Genes required for abaxial leaf development are the four KANADI (KANADI1 to KANADI4) genes, the ARF3 and ARF4 genes and the $Y A B B Y / F I L A M E N T O U S$ FLOWER genes. These genes all encode transcription factors. We concentrate here on the HD-ZIPIII and KANADI genes as these, when mutant, cause the most dramatic changes to leaf development.

Loss of HD-ZIPIII function in Arabidopsis causes varying degrees of abaxialization of leaves (Fig. 3D-F). The most severely affected leaves are bladeless prongs with abaxial traits around their circumference. Internally, these leaves often lack xylem tissue. Less severely affected leaves may be trumpet-shaped with the abaxial side of the leaf on the outside of the "bell", whereas the least severely affected leaves show downward curling. Ectopic expression of $H D$-ZIPIII genes cause a complementary set of defects in the leaf (Fig. 3A-C). HD-ZIPIII genes act partially redundantly to one another (Talbert et al. 1995; Emery et al. 2003; Prigge et al. 2005). The most extreme phenotypes are seen in revoluta phabulosa and phavoluta triple mutant seedlings. These seedlings may lack one or both cotyledons. When cotyledons are present, they are bladeless and abaxialized (Fig. 3G and H). The failure of cotyledons to form in these mutants suggests that the ad/abaxial cotyledon boundary is required not only for outgrowth of leaf blade in the lateral dimension but also in the proximal-distal dimension.

Loss of KANADI function leads to adaxialization and the plants have phenotypes similar to those seen in $H D-Z I P I I I$ gain of function mutants. The four KANADI genes also act redundantly to one another and the strongest phenotypes are seen in lines carrying mutations in three or more of the KANADI genes (Eshed et al. 1999, 2001, 2004; Kerstetter et al. 2001). Overexpression of $K A N A D I$ causes leaves to curl down or, in more severe cases, to develop without blades.

The mRNAs of HD-ZIPIII and KANADI genes accumulate in largely complementary patterns (Eshed et al. 2001; Kerstetter and Bowman 2001; McConnell et al.
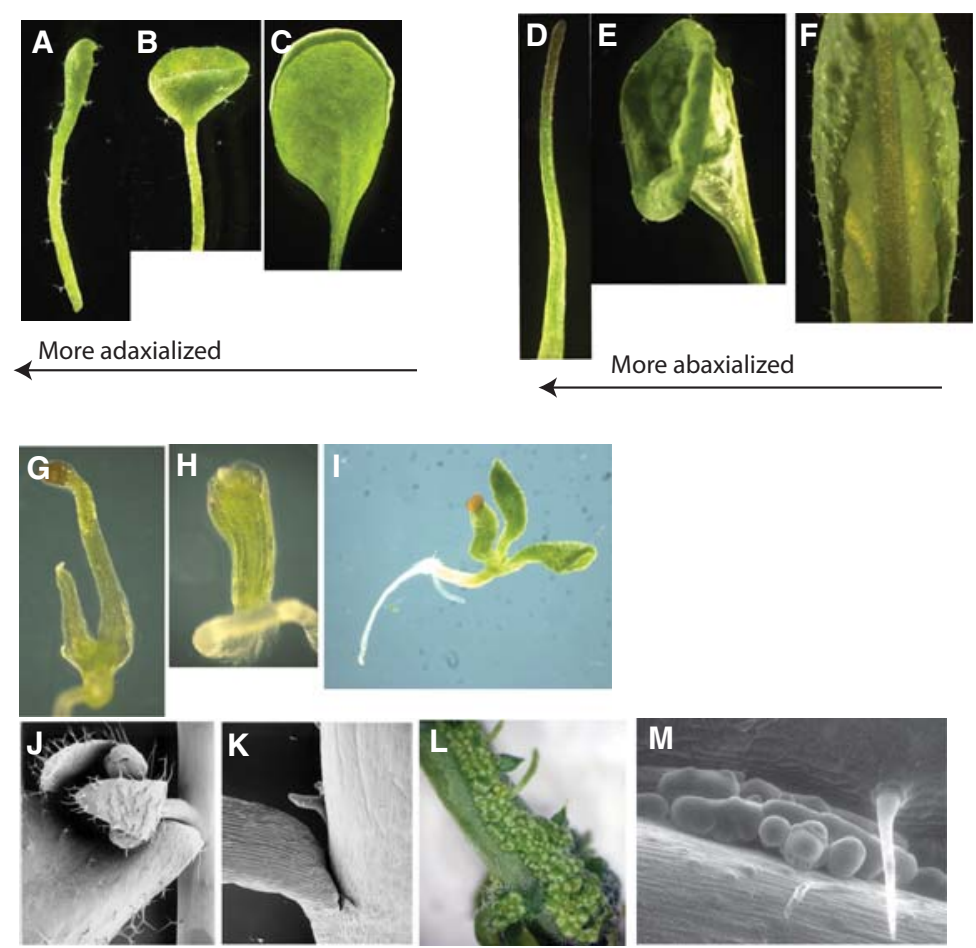

Figure 3. Mutants lacking or with excess HD-ZIPIII function show altered leaf polarity and altered patterns of shoot apical meristem formation. $(A-C)$ Leaves with ectopic HD-ZIPIII activity showing varying degrees of adaxialization. $(D-F)$ Leaves with reduced HD-ZIPIII activity showing varying degrees of abaxialization. $(G)$ phb phv rev triple mutant with two bladeless, abaxialized cotyledons and no shoot apical meristem. $(H)$ phb phv rev triple mutant lacking cotyledons and shoot apical meristem. (I) Dominant phabulosa mutant with extra and adaxialized cotyledons. $(J)$ Scanning electron micrograph of wild-type leaf axil with axillary bud. $(K)$ Scanning electron micrograph of abaxialized leaf axil lacking axillary bud. $(L)$ Plant with ectopic REVOLUTA activity showing ectopic shoot apical meristem formation along the inflorescence stem. $(M)$ Scanning electron micrograph of the early stages of ectopic meristem formation in a plant with ectopic REVOLUTA activity. 
2001; Prigge et al. 2005; Izhaki and Bowman 2007). HDZIPIII mRNAs accumulate in a central, adaxial domain of the plant that in the embryo includes the developing vasculature as well as the adaxial domains of the cotyledons and the presumptive shoot apical meristem. In the plant after germination, HD-ZIPIII genes are expressed in the vasculature, throughout the shoot apical meristem, and in the adaxial domains of the cotyledons. In the embryo, $K A N A D I$ mRNAs accumulate in the abaxial domain of the cotyledon primordia and in the peripheral regions of the hypocotyl. After germination, KANADI expression is found in the abaxial domains of leaf primordia.

\section{HD-ZIPIII AND KANADI GENES ACT OPPOSITELY TO CONTROL GROWTH}

In addition to specifying opposing polar coordinates in the leaf, $H D-Z I P I I I$ and $K A N A D I$ genes act oppositely to control new growth in the shoot.

HD-ZIPIII and KANADI genes have opposing influences on shoot apical meristem development in the embryo. The shoot apical meristem arises from a region of the embryo between the developing cotyledons (Fig. $2 \mathrm{~A}, \mathrm{~B})$ and is therefore completely contained within the larger adaxial cylinder of the embryo. In mutants lacking $H D$-ZIPIII function and therefore unable to specify an adaxial domain, no shoot apical meristem arises (Emery et al. 2003; Prigge et al. 2005). Similarly, in mutants that are abaxialized owing to ectopic KANADI activity, shoot apical meristem formation in the embryo is blocked (Kerstetter et al. 2001). Thus, it appears that the formation of the adaxial domain is a prerequisite for shoot apical meristem formation.

Although most studies to date have focused on the role of HD-ZIPIII genes in controlling polarity along the ad/ abaxial dimension, there is also evidence that these genes can control polarity along the root/shoot axis of the embryo (Grigg et al. 2009; Smith and Long 2010). In cases in which HD-ZIPIII function is expanded into the root pole of the embryo, a shoot apical meristem forms in place of a root apical meristem.

Postembryonic formation of new shoot apical meristems is also affected by HD-ZIPIII activity. New shoot apical meristems develop in the leaf axil - this is the junction where leaf and stem meet - ultimately giving rise to branches on the plant. Close examination of the formation of these new buds shows that they develop on the adaxial leaf base of Arabidopsis leaves (Long and Barton 2000). In mutants in which leaves are abaxialized, for instance when $H D$-ZIPIII activity is reduced, axillary meristems fail to form (Fig. 3J,K) (Talbert et al. 1995). Conversely, in mutants with high levels of HD-ZIPIII activity and adaxialized leaves, extra axillary meristems form on the undersides of leaves or from the epidermis of stem tissue (Fig. 3L,M) (McConnell and Barton 1998).

HD-ZIPIII proteins are not the only transcription factors that, when ectopically expressed, can cause ectopic shoot apical meristem formation. Class I KNOX genes, homeodomain containing proteins that are necessary for shoot apical formation and maintenance, can also do so
(Sinha et al. 1993; Long et al. 1996; Kerstetter et al. 1997). However, these transcription factors can only cause ectopic meristem formation from the upper/adaxial side of the leaf and not from the underside of the leaf.

Thus, HD-ZIPIII genes in particular are associated with the ability to force new shoot apical meristem formation throughout the plant. They may do so by establishing a new axis of ad/abaxial polarity. The new adaxial domain would then possess competence to allow class I KNOX genes to promote shoot apical meristem formation. The underlying molecular basis for this competence is unknown but could involve establishing the correct hormonal environment or promoting the presence of transcriptional cofactors required for class I KNOX action. However, as new shoot apical meristems that develop in response to ectopic KNOX activity show normal ad/abaxial polarity, it must follow that class I KNOX genes, although perhaps only indirectly, feed back onto the ad/ ab polarity system to generate not just meristematic cells but also a new shoot axis.

$H D-Z I P I I I$ and KANADI also affect the outgrowth of determinate organs (those with limited growth potential) as well as shoot apical meristems. As mentioned above, loss of HD-ZIPIII function is associated with loss of cotyledon outgrowth. Increased HD-ZIPIII function on the other hand can promote the formation of extra cotyledons in seedlings (Fig. 3I). Conversely, loss of KANADI function causes ectopic cotyledon formation from the hypocotyl (Izhaki and Bowman 2007), whereas extra KANADI function represses outgrowth of the integuments that form the seed coat (McAbee et al. 2006).

In summary, there is a general association between $H D$-ZIPIII action and growth promotion and between $K A N A D I$ action and growth inhibition. Our recent discovery that $H D$-ZIPIII genes promote germination whereas $K A N A D I$ genes inhibit germination (described below) is yet another case within this larger theme.

\section{IDENTIFICATION OF TARGETS OF HD-ZIPIII/REVOLUTA AND KANADI REGULATION}

To understand how the HD-ZIPIII and KANADI genes pattern the plant, we needed to find out what genes they regulate. Our goal was to identify a high confidence set of genes targeted by the HD-ZIPIII transcription factor REVOLUTA and the KANADI1 transcription factor. To do this, we generated inducible variants of these transcription factors. These were fusions of glucocorticoid responsive domains fused to the coding sequences of REVOLUTA and KANADI introduced into plants to generate separate transgenic lines (Wenkel et al. 2007; T Huang et al., unpubl.). The plants we generated, when treated with dexamethasone, showed gain of function phenotypes typical for these factors showing the gene fusions retained activity. Additional important features of this experiment were: First, we grew seedlings in liquid cultures to allow for rapid and uniform addition of the chemical inducer. Second, gene expression was assayed at three to four time points allowing us to see trends in the data. 
Third, each data point for the transgenic lines was replicated three times and each data point for the wild-type controls was replicated six times. Fourth, the experiments were analyzed using a two-way ANOVA and targets were those transcripts showing an interaction between genotype and time (corrected $p<0.01$ ) providing a statistically powerful way to identify likely targets (BJ Reinhart et al., unpubl.; T Huang et al., unpubl.).

For any gene we identified as a likely target based on the time course data, we required at least one additional piece of independent evidence in support of its relevance to the ad/abaxial regulatory pathway. Additional evidence was any of the following: Mutations in the target gene, either loss or gain of function, cause a change in leaf development or shoot apical meristem formation. The candidate target gene is regulated oppositely by REVOLUTA and KANADI. The candidate target gene is adjacent to a CHIP defined binding site for REVOLUTA or KANADI. The candidate target gene is expressed in a pattern limited to a relevant subdomain of the leaf or shoot apical meristem. The protein encoded by the candidate gene physically interacts with REVOLUTA. There is evidence for evolutionary conservation of the regulator-target relationship. In this way, a set of $>100$ high confidence targets of REVOLUTA and/or KANADI has been assembled (BJ Reinhart et al., unpubl.; T Huang et al., unpubl.).

\section{MECHANISM OF ACTION OF REVOLUTA AND KANADI} REVOLUTA

The REVOLUTA (REV) transcription factor is one of five class III homeodomain leucine zipper HD-ZIP proteins encoded in the Arabidopsis genome (Sessa et al. 1998). They are named for the DNA binding homeodomain at their amino terminus which is followed immediately by a leucine zipper domain. The leucine zipper mediates dimerization with other HD-ZIPIII proteins. The dimers bind a palindromic sequence of DNA in vitro. The proteins are large, almost 1000 amino acids in length, and in addition to the HD-ZIP motif include a START domain, a domain of unknown function and a PAS related domain (Mukherjee et al. 2009). The START domain is related to the ABA binding domain in the PYR ABA receptor (Park et al. 2009) and is predicted to bind an as yet unknown hydrophobic ligand. The PAS domain inhibits dimerization of REV proteins in yeast and is hypothesized to be the target of as yet unknown signals that lift this repression (Magnani and Barton 2011).

REVOLUTA proteins interact with many types of transcription factors in yeast. Chandler et al. (2007) found that the HD-ZIPIII protein PHAVOLUTA interacts with the AP2 family DORNRÖSCHEN and DORNRÖSCHENLIKE transcription factors. Moreover, dornröschen dornröschenlike double mutants fail to make cotyledons indicating that the interaction has biological relevance. In our studies, we have found that REVOLUTA interacts in yeast two hybrid assays with several types of transcription factors. These include TCP type, IDD type, and ARR type proteins. In some cases, the interacting factors are encoded by genes targeted by REVOLUTA indicating they form a feedback loop. In other cases, the corresponding factor, when overexpressed alters leaf development.

REVOLUTA binding sites are found upstream of, downstream from and within the genes they regulate, suggesting that REVOLUTA may act as part of an enhancer binding complex. The majority of genes showing changes in transcript abundance following REVOLUTA induction are up-regulated indicating a role for REVOLUTA as an activator of transcription. Consistent with this, we find the in vitro defined DNA binding site for HD-ZIPIII proteins to be overrepresented upstream of genes that are up-regulated following REVOLUTA induction. Genes that are down-regulated do not show this enrichment. However, in a few cases, we have identified genes that are downregulated following REVOLUTA induction that also are adjacent to REVOLUTA binding sites. This suggests that there may be contexts in which REVOLUTA may act as a negative regulator of transcription.

We hypothesize that REVOLUTA acts together with additional proteins to activate and possibly also repress gene expression. Given the many tissues and life stages affected by REVOLUTA, it seems likely that these additional proteins play an important role in directing REVOLUTA action to cell or tissue specific targets. Indeed, based on the expression pattern of ZPR3, a known target of REVOLUTA (Wenkel et al. 2007), we know that not all REVOLUTA expressing cells express ZPR3. This argues that REVOLUTA alone is not sufficient to activate ZPR3. Activation and/or inhibition of REVOLUTA by ligand binding to the START domain or signal transduction through the PAS domain likely provide additional mechanisms by which interactions between REVOLUTA and interacting partners are controlled.

\section{KANADI}

KANADI proteins belong to the GARP subfamily of MYB domain proteins (Hosoda et al. 2002). These proteins have a single DNA binding MYB repeat. Other members of this subfamily include the ARR proteins that mediate cytokinin-regulated transcription. Although some GARP family members appear to bind DNA as dimers, all evidence to date indicates that KANADI binds DNA as a monomer ( $T$ Huang et al., unpubl.). In vitro KANADI binds to a short sequence that is distinct from the sequence to which the ARR type GARP proteins bind (T Huang et al., unpubl.). The best defined target of KANADI regulation to date is ASYMMETRIC2, a LOB domain transcription factor that promotes adaxial leaf development. A point mutation in a KANADI binding site just upstream of the transcriptional start site is sufficient to cause this gene to be ectopically expressed (Wu et al. 2008).

The majority of transcripts changing in response to KANADI activation are down-regulated consistent with the evidence to date that KANADI is a transcriptional repressor. Consistent with this, the in vitro defined DNA binding site for KANADI protein is overrepresented 
upstream of genes that are down-regulated following KANADI induction. Genes that are up-regulated in response to KANADI induction do not show this enrichment (T Huang et al., unpubl.).

KANADI proteins bind to the TOPLESS corepressor in yeast (Causier et al. 2012). Thus, one mode of action of KANADI could be to recruit TOPLESS and associated chromatin-modifying enzymes to genes targeted for repression. KANADI has also been shown to physically interact with ARF3, a protein that contains a transcriptional repression domain (Kelley et al. 2012) and that has been shown to be required for KANADI inhibition of growth in floral organs (Pekker et al. 2005). Thus, KANADI may inhibit transcription at target loci by more than one mechanism.

\section{What molecular mechanism underlies the opposite action of HD-ZIPIII and KANADI factors?}

Two models, based on phenotypic and histological analyses, have been proposed for the interaction between the oppositely acting HD-ZIPIII and KANADI factors. In one model, the two types of gene products act antagonistically to one another, inhibiting each other (Eshed et al. 2001). The other model invokes a balance mechanism in which the amount of HD-ZIPIII activity relative to KANADI activity is measured by the cell (Kelley et al. 2009). Our analysis of the effects of inducible REVOLUTA and KANADI provide support for both types of model and suggest that more than one type of opposite interaction among these actors has arisen over the course of evolution (Fig. 4).

The discovery that REVOLUTA is primarily an activator of transcription, whereas KANADI is primarily a repressor of transcription sets up a mechanistic context in which these two transcription factor types can naturally have opposing effects. Indeed, we have found that there exists a subset of genes at which REVOLUTA and KANADI both act directly and oppositely (Fig. 4A) (Brandt et al. 2012; BJ Reinhart et al., unpubl.). Thus, one way REVOLUTA and KANADI can have opposing effects is by their opposing action on common targets. We have called such common, oppositely regulated, targets ORK genes for oppositely regulated in REVOLUTA and KANADI. They include Class II HD-ZIP genes, genes involved in ABA signaling (see below), a gene required for auxin biosynthesis, a transcription factor that controls epidermal traits, and a gene of unknown function. Opposite action of an activator and a repressor on the same promoter could support either a balance model or an antagonism model depending on the molecular interaction of the factors.

We also find that KANADI3 transcript levels decrease within two hours of REVOLUTA induction. It is not known if this is a direct or indirect effect, but either way it reflects an antagonistic interaction on KANADI by REVOLUTA. No reciprocal effect on HD-ZIPIII transcription by KANADI was detected indicating this type of antagonism does not appear to be mutual.

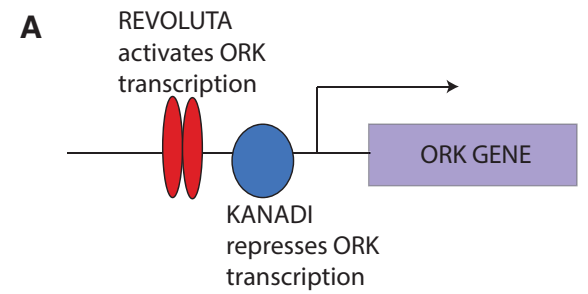

B

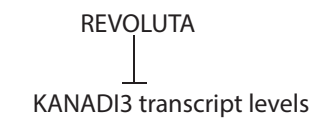

\begin{tabular}{lll}
$\mathbf{C} \begin{array}{l}\text { Auxin } \\
\text { biosynthesis }\end{array}$ & $\begin{array}{l}\text { TAA1 } \\
\text { YUC5 }\end{array} \quad \mathrm{R} \uparrow$ \\
$\begin{array}{l}\text { Auxin } \\
\text { transport }\end{array}$ & PIN4 & $\mathrm{K} \downarrow$ \\
\hline $\begin{array}{l}\text { Modifiers of } \\
\text { direction of } \\
\text { auxin transport }\end{array}$ & NPY1 & $\mathrm{R} \uparrow$ \\
& NPY3 & $\mathrm{K} \downarrow$ \\
& WAG1 & $\mathrm{R} \uparrow$ \\
& WAG2 & $\mathrm{K} \downarrow$ \\
& & \\
\hline Auxin signaling & FLS2 & $\mathrm{K} \downarrow$ \\
& IAA2 & $\mathrm{K} \downarrow$ \\
& IAA18 & $\mathrm{R} \uparrow$
\end{tabular}

Figure 4. Mechanisms underlying opposite actions of $H D$ ZIPIII (REVOLUTA) and KANADII transcription factor genes on plant development. (A) REVOLUTA and KANADI1 share a set of common targets dubbed $O R K$ genes for "Oppositely regulated by REVOLUTA and KANADI". (B) REVOLUTA negatively regulates KANADI3 transcript levels within two hours of REVOLUTA induction. It is unknown whether this regulation is direct or indirect. (C) REVOLUTA and KANADI oppositely regulate multiple steps in the auxin pathway. In some cases, they act oppositely on a single target (TAA1; Brandt et al. 2012). In other cases, they act oppositely on different members of the same gene family ( $N P Y$ and $W A G$ genes). (i) Indirect regulation.

Third, in some cases REVOLUTA and KANADI act oppositely on different components of a proposed pathway. An example of this is their action on members of the NPH3 and AGC3 KINASE gene families. NPH3-like proteins and AGC3 kinases are thought to act together in a pathway that determines what face of the cell the PIN auxin exporter accumulates at (see Spalding 2013 for review). Thus, NPH3-like proteins and AGC3 kinases together determine the direction of auxin transport. The NPY genes (there are five of them) are a subset of NPH3-like genes that together with the WAG and PID AGC3 kinases (there are four of them) are required for lateral organ outgrowth (Furutani et al. 2007, 2011). REVOLUTA activates, probably directly, transcription of NPY1 and WAG1, whereas KANADI represses, probably indirectly, NPY3 and WAG2 (T Huang et al., unpubl.). Thus, unlike the case of the auxin biosynthetic gene $T A A 1$ or the other $O R K$ genes mentioned above, opposite regulation does not appear to occur on the same locus but on different members of a gene family. 
(Note that whereas the emphasis here is on genes or pathways that are oppositely regulated by REV and KANADI, many of the genes and pathways targeted by REVOLUTA and KANADI are targeted by one and not the other. In addition, among shared targets, we find cases of regulation in the same direction such as IDD4 (mentioned below) which is down-regulated by both REVOLUTA and KANADI.)

\section{INTERACTION OF THE AD/ABAXIAL REGULATORY PATHWAY WITH HORMONE PATHWAYS}

As described above, REVOLUTA generally promotes growth, whereas KANADI generally inhibits growth. Among the target genes oppositely regulated by REVOLUTA and KANADI are genes involved in the biosynthesis and/or signaling of nearly all the major plant hormones: abscisic acid (ABA), brassinolide, gibberellin, strigolactone and auxin. In addition, although we did not identify it in our study, Ioio et al. (2012) found that the HD-ZIPIII gene PHABULOSA activates transcription of a gene encoding a cytokinin biosynthetic enzyme. As all of these hormone pathways control growth in some way, it is likely that, as a general principle, HD-ZIPIII and $K A N A D I$ act to create cellular environments that either promote or inhibit the action of these hormones.

\section{Abscisic acid control of the ad/abaxial regulatory pathway}

Striking among the genes we found regulated by REVOLUTA and KANADI are genes that mediate ABA signaling. These are striking because two of the more prominent $O R K$ genes encode likely ABA signaling components (one a SnRK3 kinase, the other a member of the ABA receptor gene family), because of the large number of members of these gene families that showed regulation (BJ Reinhart et al., unpubl.; E Magnani et al., unpubl.) and because there was no previous evidence linking ABA signaling to regulation of ad/abaxial leaf polarity.

The finding that genes involved in ABA signaling were oppositely regulated by REVOLUTA and KANADI prompted us to explore whether HD-ZIPIII or KANADI mutants showed defects in processes regulated by ABA. One of the classic ABA functions is to promote seed dormancy and prevent germination. In fact, the first described mutants in the KANADI4 gene, called ats, were identified based on their seed coat and germination properties (Leon-Kloosterziel et al. 1994). Tests on loss and gain of function HD-ZIPIII and KANADI mutants showed that $H D-Z I P I I I$ activity promotes germination, whereas $K A N A D I$ inhibits it (E Magnani et al., unpubl.). When the same experiments were performed in the presence of ABA, kanadi1 kanadi 2 kanadi 3 loss of function mutants still germinated faster than the matched wild-type controls indicating that ABA acts upstream of KANADI. Similarly, gain of function REVOLUTA mutants germinated faster than their matched wild-type controls indicating that HD-ZIPIII action is also downstream from ABA signaling.

The schematic in Figure 5C summarizes these results. ABA acts upstream of, and opposes, HD-ZIPIII (REVO$L U T A)$ action. Consistent with this, we find that a significant number of genes up-regulated by REVOLUTA are down-regulated by ABA. Some but not all of the inhibition of REVOLUTA action by ABA likely acts through an increase in mir165 levels (E Magnani et al., unpubl.). Mir165 is the microRNA that directs spatial restriction of HD-ZIPIII mRNA accumulation (Fig. $2 \mathrm{~F}-\mathrm{H}$ ). In the embryo, it is expressed in the abaxial epidermis of the embryo and is thought to move inward to limit $H D$ ZIPIII accumulation to the central portion of the embryo (BJ Reinhart et al., unpubl.). Whether ABA regulates mir165 during embryogenesis or at any stage of leaf development, and therefore influences pattern formation, has yet to be determined.

ABA acts upstream of KANADI to promote efficient germination (Fig. 5C). Consistent with this, we find that many of the genes down-regulated by KANADI are also down-regulated by ABA. To date, most of the studies on ABA mediated transcriptional changes have concerned genes that are up-regulated in response to ABA (Guo et al. 2011). We find no evidence of overlap between ABA up-regulated genes and the ad/abaxial pathway. Much less is known about genes that are down-regulated by ABA and it may be that KANADI proteins play a role in this particular aspect of ABA mediated gene regulation. For the genes that are down-regulated by both ABA and KANADI, ABA signaling may act through another as yet unidentified transcriptional repressor or it may stimulate KANADI repression of these genes.

The studies we have carried out so far are limited to the interaction of ABA and the HD-ZIPIII and KANADI ad/ abaxial regulators on seed germination. ABA treatment of growing plants generates a variety of plant responses; these include changes in leaf shape, leaf size, chlorophyll content and meristem activity (T Liu et al., unpubl.). It will be important to determine if REVOLUTA and KANADI functions are involved in mediating ABA action on the plant. If so, this could represent a nexus between abiotic stress and leaf development and a mechanism by which leaf shape can be altered in response to the environment.

\section{REVOLUTA and KANADI control the auxin pathway at many steps}

Both the auxin signaling pathway and the ad/abaxial pathway are critical to the formation of cotyledons. So far, the connection between these two pathways has been unclear. Our finding that genes representing every step in the auxin pathway-from synthesis, through transport and its regulation, to signaling — are regulated by REVOLUTA and/or KANADI indicates that one of the major roles of the ad/abaxial pathway is to pattern auxin accumulation and signaling to effect cotyledon outgrowth.

High local concentrations of auxin are thought to direct patches of cells within the shoot apex to form new leaf 


\section{OF BLADES AND BRANCHES}

A

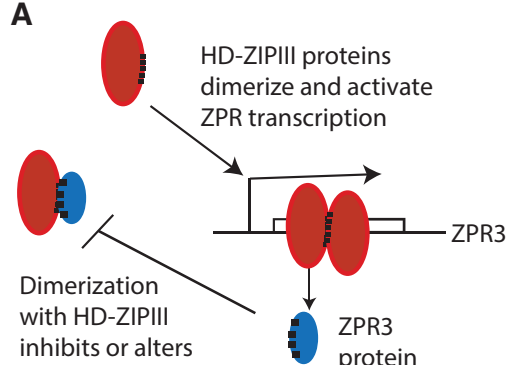

inhibits or alters protein
B

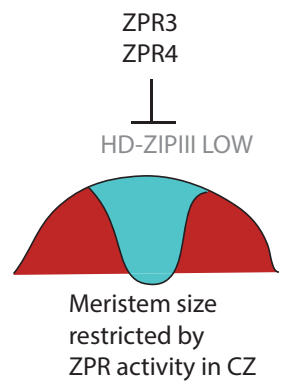

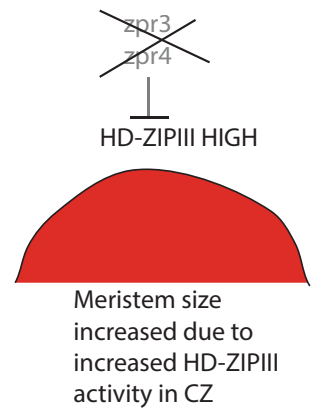

HD-ZIPIIII

C

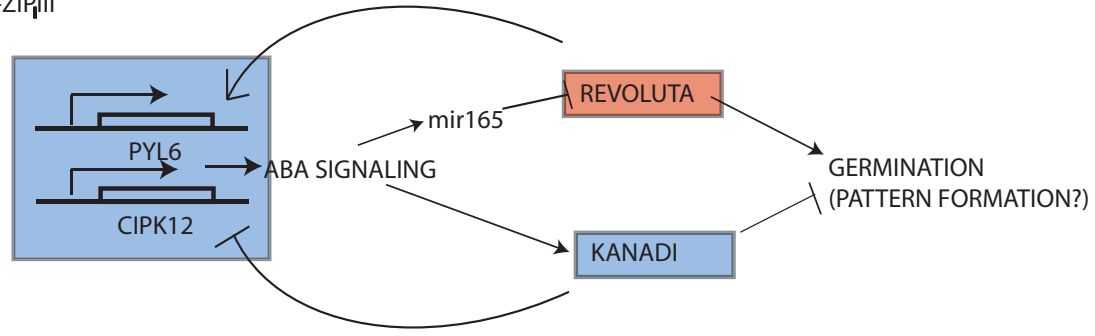

D

AGO1: Slicer activity present throughout embryo degrades HD-ZIPIII mRNA in presence of diffusible mir165
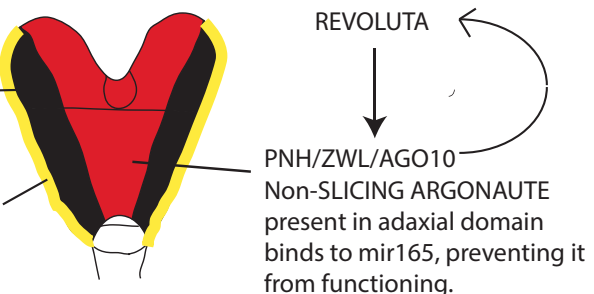

E

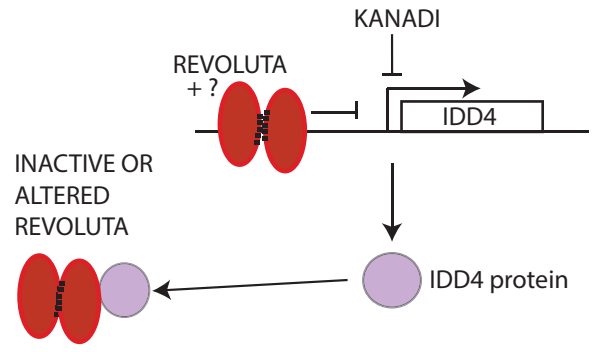

$\mathbf{F}$

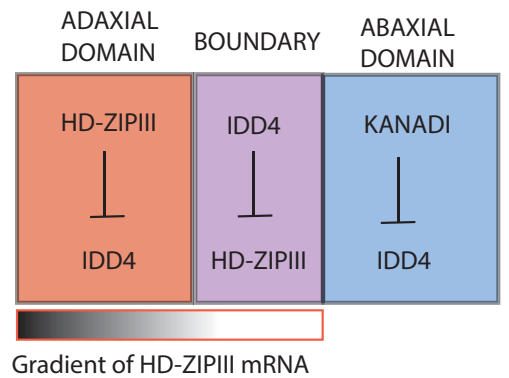

Figure 5. Feedback loops discovered by identification of targets of HD-ZIPIII/REVOLUTA and KANADI regulation. (A) REVOLUTA and LITTLE ZPR (ZPR) genes form a negative feedback loop. REVOLUTA activates transcription of four LITTLE ZIPPER genes. These are transcribed and translated to generate small proteins consisting of a small leucine zipper similar to that of the much larger HD-ZIPIII proteins. These form dimers with HD-ZIPIII proteins and either prevent them from binding DNA or alter the specificity of DNA binding. (B) Model for action of LITTLE ZIPPER3 and LITTLE ZIPPER4 in the shoot apical meristem. ZPR3 and ZPR4 act to inhibit HD-ZIPIII activity in the central zone, thus limiting the size of the shoot apical meristem. In their absence, increased HD-ZIPIII activity results in an enlarged shoot apical meristem which in turn can generate more organ primordia. $(C)$ REVOLUTA and KANADI together form a negative feedback loop with the ABA signaling pathway. (D) REVOLUTA and ARGONAUTE 10/ PINHEAD/ZWILLE form a positive feedback loop. $(E)$ IDD4 and REVOLUTA mutually regulate one another. $(F)$ Model for hypothesized ad/abaxial boundary specific expression of IDD4 based on mutual negative regulation between REVOLUTA and IDD4 and an underlying gradient of HD-ZIPIII levels.

primordia (Reinhardt et al. 2000, 2003; Heisler et al. 2005). Consistent with this, mutations that disrupt auxin biosynthetic enzymes, auxin transport, regulators of the direction of auxin transport or auxin-regulated transcription factors cause failure to form cotyledons (for review, see Möller and Weijers 2009). Conversely, addition of auxin transport inhibitors to globular stage embryos of Indian mustard, cause the apical portion of the embryo to develop a single tube-shaped cotyledon rather than two bilaterally symmetrical cotyledons (Liu et al. 1993). 
This is consistent with a model in which high auxin concentrations at two positions on the flanks of the globular embryo direct cotyledon outgrowth, whereas low auxin concentrations at the junctions between them result in no outgrowth. It is worth noting that the single tubeshaped cotyledon that developed in the auxin transport inhibitor treated mustard embryos showed normal ad/abaxial polarity. This indicates that disrupting auxin transport had no effect on the establishment of ad/abaxial polarity in this experiment.

Figure 6 diagrams the stages in patterned polar auxin transport during Arabidopsis embryogenesis. Auxin transport switches direction several times during embryogenesis. In the two-celled embryo (not shown), auxin is transported upward from the basal cell into the apical cell. By early globular stage, transport has switched direction and auxin is transported basally. Later globular stage embryos show bidirectional auxin transport with auxin flowing upward in the peripheral/abaxial domain and downward in the central/adaxial domain of the embryo. As embryos transition from globular to heart stage, new pathways of auxin transport form at the apical pole of the embryo. These streams of auxin are directed away from the apex, outward onto the flanks of the embryo. These streams collide with the upwardly direct streams at the ad/ abaxial boundary. This is also the position at which a high local concentration of auxin is found and at which cotyledon outgrowth occurs. Transport occurs primarily by the action of polarized efflux carriers or PIN proteins. These are typically asymmetrically located along one of side of the cell. This asymmetric localization is what causes auxin to flow in a coordinated direction. The choice of which side of the cell PIN proteins accumulate at is determined in part by the action of NPH3 proteins and AGC3 kinases, and in part by a mechanism that senses and responds to the relative concentration of auxin in the surrounding cells (Heisler et al. 2005; Cheng et al. 2007, 2008; Möller and Weijers 2009; Dhonukshe et al. 2010; Furutani et al. 2011; Spalding 2013).

As mentioned above, loss of HD-ZIPIII function results in failure to form cotyledons, whereas extra $H D$ ZIPIII function causes the formation of additional cotyledons (Fig. 3). Izhaki and Bowman (2007) have shown that the local high concentrations of auxin found in wildtype cotyledon primordia do not form in HD-ZIPIII loss of function mutants (i.e., phabulosa phavoluta revoluta triple mutants) that lack cotyledon development. Furthermore, they showed that kanadil kanadi2 kanadi4 triple mutants that form ectopic cotyledons from the hypocotyl also showed corresponding ectopic auxin maxima and altered localization of PIN transporters. This led them to propose that the HD-ZIPIII and KANADI ad/abaxial polarity regulators were responsible for regulating responsiveness to and/or flow of auxin in the embryo.

Examination of the set of genes regulated by REVOLUTA and KANADI reveals that genes involved in auxin biosynthesis, transport, regulation of transport, and signaling are regulated by the ad/abaxial regulatory pathway (Figs. 4C and 6) (T Huang et al., unpubl.).

REVOLUTA and KANADI oppositely regulate transcription of the auxin biosynthetic gene TAA1 (Fig. 6) (Brandt et al. 2012; BJ Reinhart et al., unpubl.). TAA1 mRNA has been shown to accumulate in an adaxial apical position in the globular embryo (Stepanova et al. 2008). This position is consistent with the spatial patterning expected from activation by REVOLUTA and repression by

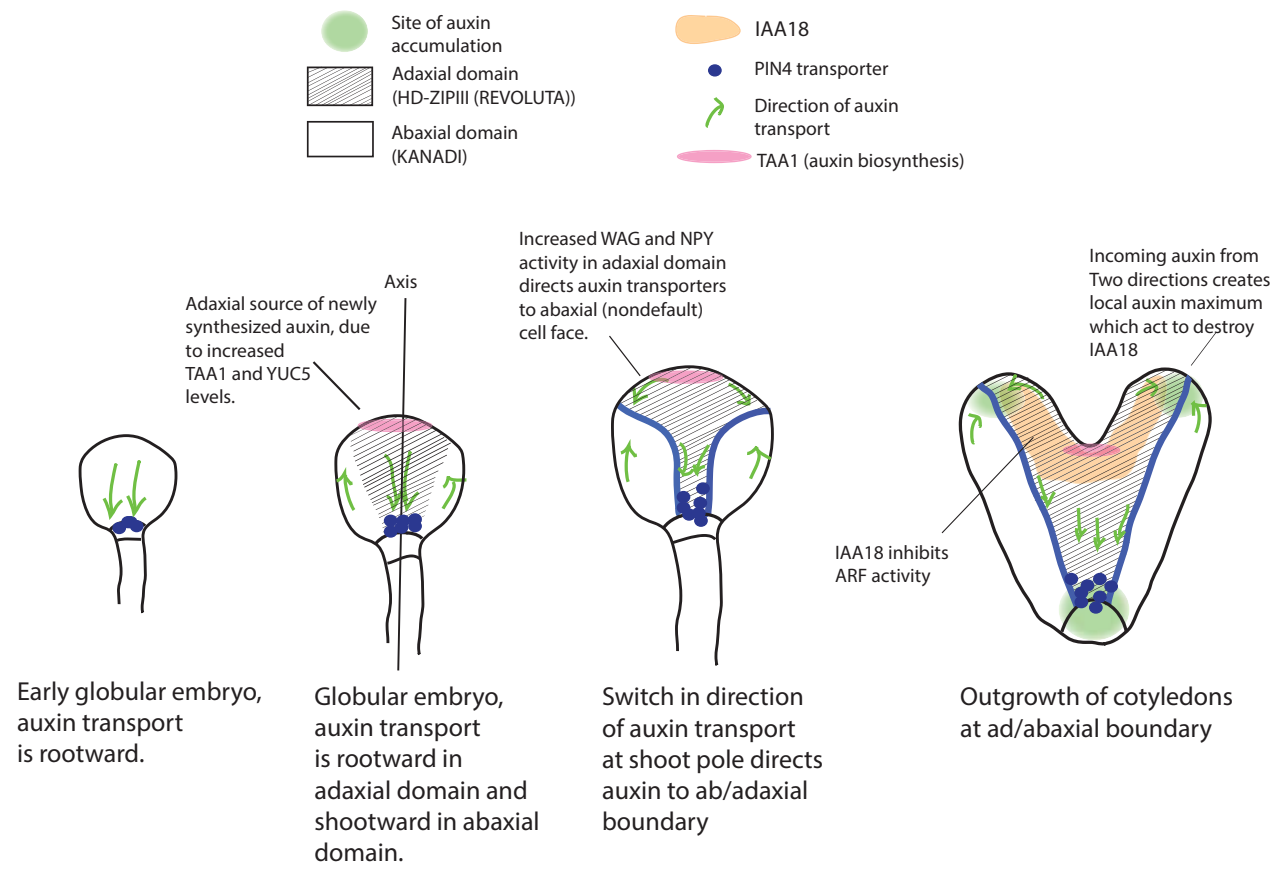

Figure 6. Pattern of auxin biosynthesis, transport, and accumulation in Arabidopsis embryos and its regulation by the ad/abaxial polarity pathway. 
KANADI. It is unknown what significance the localization of auxin biosynthetic genes has for the development of the embryo as models describing the transport and accumulation of auxin can be developed that assume spatially homogenous auxin biosynthesis (see, e.g., Jönsson et al. 2006).

KANADI negatively regulates the PIN4 auxin efflux transporter that directs auxin toward the root pole in the globular embryo (T Huang et al., unpubl.). The pattern of auxin "circulation" in the globular embryo-that is, a downward current in the center of the embryo and an upward current in the periphery-is evidence of radial, or ad/abaxial, patterning of auxin transport at this stage. It is possible that KANADI promotes this pattern of auxin flow by turning off PIN4 in the peripheral regions of the embryo.

REVOLUTA up-regulates, probably directly, expression of the NPY1 and WAGl genes, whereas KANADI down-regulates, probably indirectly, expression of NPY3 and WAG2 (BJ Reinhart et al., unpubl.; T Huang et al., unpubl.). NPY family genes encode BTB-POZ domain proteins that together with AGC3 kinases determine which face of the cell the PIN efflux transporters localize to and thereby also determine the direction of auxin transport (Cheng et al. 2007, 2008; Dhonukshe et al. 2010; Furutani et al. 2011). Opposite action of REVOLUTA and KANADI on these regulators of PIN polar localization would predict that the REVOLUTA and KANADI expressing domains direct their PIN proteins to opposing walls and hence direct auxin in opposing directions. Such a mechanism could explain the opposing directions of auxin transport observed in the adaxial and abaxial domains of the presumptive cotyledons (Fig. 6).

Finally some key elements of the auxin signal transduction pathway are regulated by REVOLUTA and KANADI. KANADI down-regulates FLS2, a protein that mediates flagellin-induced expression of miR393a, a miRNA that in turn targets the mRNA for the auxin receptor TIR1 (Navarro et al. 2006). Down-regulation of $F L S 2$ would be expected to increase auxin receptor levels and thereby alter the auxin sensitivity of KANADI expressing cells-REVOLUTA increases expression of the IAA1 8 transcriptional repressor (T Huang et al., unpubl.). The IAA18 protein acts as a repressor of transcription unless auxin is present. Mutants in which IAA18 is made insensitive to auxin mediated degradation fail to form cotyledons (Ploense et al. 2009). This regulation is probably direct as there is an HD-ZIPIII binding site adjacent to $I A A 18$ (T Huang et al., unpubl.; Brandt et al. 2012). IAA $18 \mathrm{mRNA}$ accumulates primarily in the adaxial cotyledon domains (Ploense et al. 2009) consistent with up-regulation by REVOLUTA. Thus, KANADI is predicted to change the overall responsiveness to auxin by turning up levels of the TIR1 auxin receptor, whereas REVOLUTA puts in place a particular IAA type auxin inhibitor and, in doing so, may tune the sensitivity of the adaxial domain to respond to a particular critical concentration of auxin.

In summary, we have found that the HD-ZIPIII and KANADI regulators of ad/abaxial polarity influence transcription of genes associated with auxin biosynthesis, transport and signaling. This is consistent with the hypothesis that the ad/abaxial regulatory network controls the spatial pattern of auxin accumulation and responsiveness and suggests specific hypotheses for how this patterning comes about. We have discussed this regulation in the context of patterning cotyledon development. Of the several steps in auxin action we have identified as regulated by REV and/or KAN, it is possible that one is the critical step for cotyledon formation. This is the way we are used to seeing developmental genetic pathways work. However, this may be an artifact of the way we have approached the problem in the past. By searching for mutants with phenotypes that show clear transformation of developmental fates, or for genes that show large changes in transcript levels, we may have biased ourselves toward the study of developmental events that occur via major changes in the activity or quantity of one critical actor. The ability to survey entire genomes for responses to developmental regulators such as REVOLUTA and/or KANADI makes it possible to rapidly identify, as we have here, most of the regulated components of a given pathway. Regulation of auxin action at so many points suggests that instead of regulating a key gene to achieve the desired endpoint - that is, the accumulation and perception of high auxin concentrations at the sites of the presumptive cotyledons-REVOLUTA and KANADI may achieve this by their cumulative action on several minor regulatory steps.

\section{FEEDBACK LOOPS}

Several of the targets of REVOLUTA and KANADI that we discovered in our study turn out to be part of feedback loops. The first feedback loop we identified was the negative feedback loop involving the LITTLE ZIPPER family of genes (Fig. 5A). We identified the LITTLE ZIPPER2 gene as a gene that is up-regulated by REVOLUTA in an early pilot screen (Wenkel et al. 2007). The predicted structure of ZPR2 indicates that it is a small protein that consists almost solely of a leucine zipper similar to that found in HD-ZIPIII proteins. This suggested the hypothesis, later tested and borne out, that LITTLE ZIPPER proteins act to inhibit dimerization and DNA binding of HD-ZIPIII proteins. Loss of function mutants for LITTLE ZIPPER genes show that one of the consequences of knocking them out is enlargement of the shoot apical meristem (Kim et al. 2008). LITTLE ZIPPER3 is expressed in the central zone of the shoot apical meristem indicating it may be important to limit, or alter, HD-ZIPIII activity in this domain to regulate meristem size (Fig. 5B).

The second feedback loop, also a negative feedback loop, identified is one in which REVOLUTA and KANADI feedback on ABA signaling. As described above, REVOLUTA action is down-regulated by ABA signaling. REVOLUTA activates transcription of PYL6 and CIPK12, two predicted components of ABA signaling pathway. KANADI on the other hand is up-regulated 
by ABA and feeds back to decrease levels of PYL6 and CIPK12 (Fig. 5C).

A third negative feedback loop involves KANADI1 feeding back on the activity of the related KANADI loci (BJ Reinhart et al., unpubl.). In response to KANADI1 induction, levels of KANADI2 and KANADI3 are reduced.

A fourth feedback loop, this one positive, involves the microRNA that controls the spatial extent of HD-ZIPIII mRNA accumulation (Fig. 5D). MicroRNAs 165 and 166 negatively regulate the HD-ZIPIII mRNAs causing them to be degraded (Mallory et al. 2004). The promoters driving HD-ZIPIII transcription - at least in the case of PHABULOSA, appear to be near constitutively expressed throughout the embryo (Fig. 2F). MicroRNA 165 is expressed in the abaxial epidermis and is thought to move internally, thus setting up a gradient of HD-ZIPIII expression (Fig. 2C,D,G,H) (BJ Reinhart et al., unpubl.). Degradation of HD-ZIPIII mRNA is thought to occur by the association of mir165/166 with ARGONAUTE1, an endonuclease. Zhu et al. (2011) have recently presented data that another argonaute family member, ARGONAUTE10, also known as PINHEAD/ZWILLE, lacks endonuclease activity in vivo and instead acts to sequester microRNAs165/166 so that they cannot act on their HD-ZIPIII targets. In embryos, PINHEAD/ZWILLE mRNA is expressed in the adaxial domain in a pattern that is very similar to that of HD-ZIPIII (Lynn et al. 1999) consistent with transcriptional activation of PINHEAD/ZWILLE by REVOLUTA. Thus, REVOLUTA would activate PINHEAD/ZWILLE transcription, which would then act to protect the integrity of HD-ZIPIII mRNA, forming a positive feedback loop.

\section{REVOLUTA AND KANADI REGULATE SUBSIDIARY TRANSCRIPTION FACTORS AND LIGANDS TO CONTROL TISSUE SPECIFIC AD/ABAXIAL POLAR DEVELOPMENT}

Another common finding in our set of genes targeted by REVOLUTA and/or KANADI are genes that encode transcription factors. As REVOLUTA and KANADI control polarity in many tissue types and at many life stages, it is not surprising that one mode of action of these proteins is to call on subsidiary transcription factors and ligands to execute subprograms in development. One example is the control of vascular polarity by REVOLUTA by known regulators as described below.

In Arabidopsis, the vascular bundles are polarized with xylem located adaxially and phloem located abaxially. Between the xylem and the phloem is a region of stem cells, called the cambium. The descendants of these stem cells give rise to new stem cells just like themselves as well as new xylem cells or new phloem cells depending on which side of the cambium they are formed. The CLE 41 peptide ligand is produced in phloem cells where it inhibits xylem differentiation and stimulates ordered division of the adjacent stem cells (Etchells and Turner 2010). The APL transcription factor is also made in phloem cells where it acts to both promote phloem development and to repress xylem differentiation (Bonke et al. 2003). Transcripts of both APL and CLE41 are downregulated within 2 hours of REVOLUTA induction. It is unknown if this regulation is direct or indirect. Thus, we hypothesize that REVOLUTA acts to polarize vascular tissue by repressing transcription of APL and CLE41 in cells destined to become xylem cells.

\section{DISCOVERING NEW ACTORS IN THE AD/ABAXIAL NETWORK: THE HD-ZIPIIS AND IDDS}

Among the targets of REVOLUTA and KANADI regulation are genes of unknown function. One group of these are the class II HD-ZIP proteins. HD-ZIPII proteins are distant relatives of HD-ZIPIII factors that appear to act predominantly as transcriptional repressors (Ciarabelli et al. 1993). Identification of HAT2, along with several of its relatives, as a gene oppositely regulated by REVOLUTA and KANADI led ultimately to finding that a subset of HD-ZIPII proteins also play a role in the development of ad/abaxial leaf polarity (Bou-Torrent et al. 2012).

Many pieces of evidence point to the zinc finger transcription factor IDD4 as a part of the ad/abaxial regulatory network (BJ Reinhart et al., unpubl.): Transcription of IDD4 is negatively regulated by both REVOLUTA and by KANADI; A binding site for REVOLUTA which flanks IDD4 suggests that REVOLUTA acts as a direct regulator; IDD4 protein physically interacts with REVOLUTA in yeast two hybrid experiments; When overexpressed, IDD4 causes leaf down curling - a sign of abaxialization; IDD4 is a member of a gene family of which many members are regulated and therefore for which the regulator-target connection is likely to be ancient. The abaxialized phenotype caused by IDD4 suggests that it inhibits REVOLUTA action. Thus, REVOLUTA and IDD4 share a mutually antagonistic relationship (Fig. 5).

The exact role of IDD4 in leaf development awaits the study of loss of function mutations in this gene. However, its membership in a greater family of genes involved in setting up boundaries between radial domains in the hypocotyl suggests that IDD4 might act at the boundary between ad- and abaxial domains of the leaf.

As an illustration of how this might work, consider the $J A C K D A W$ locus, a gene related to IDD4. As with IDD4 and several other members of the IDD gene family, $J A C K D A W$ is down-regulated by both KANADI and REVOLUTA and is located adjacent to a REVOLUTA binding site (BJ Reinhart et al., unpubl.). JACKDAW is expressed in a layer between the vascular cylinder and the outer hypocotyl layers that is in roughly the location of the predicted ad/abaxial boundary (Welch et al. 2007). Negative regulation of JACKDAW by REVOLUTA and by KANADI could explain how its expression is limited to the boundary if neither REVOLUTA nor KANADI is active in the boundary itself. The graded mRNA levels seen for HD-ZIPIII mRNA in the embryo (Fig. 2) 
suggests that expression of HD-ZIPIII would be lower at the boundary than more adaxially. Thus, if JACKDAW, as IDD4, negatively regulates REVOLUTA, it may win out and keep HD-ZIPIII activity off. Figure 5 illustrates a model for how boundary specific expression of IDD4 could come about given the mutual negative regulation between it and HDiZIPIII proteins, and an underlying gradient of HD-ZIPIII levels.

\section{HD-ZIPIII GENES, KANADI GENES AND THE EVOLUTION OF PLANT DEVELOPMENT}

There are two major lineages of green algae - the chlorophyte algae and the charophyte algae. Land plants arose from an ancient member of the charophyte lineage (Bhattacharya and Medlin 1998). GARP type MYB genes have been found in the chlorophyte algae where one member, PSR 1, is involved in phosphorous metabolism (Wykoff et al. 1999). HD-ZIPIII genes have so far only been found in the charophyte algae indicating they may be younger than GARP type MYB genes (Floyd et al. 2006). It is notable that the microRNA that limits HD-ZIPIII spatial expression in Arabidopsis, mir166, is also present in charophyte algae indicating that control of HD-ZIPIII mRNAs by microRNAs preceded land plant evolution (Floyd et al. 2006).

Charophyte algae and basal (nonvascular) land plants lack many of the tissues and organs we know to be affected by KANADI and HD-ZIPIII genes in higher plants - for instance they lack leaves, vasculature, roots and seeds. What then, might the role of KANADI and HD-ZIPIII genes be in algae and primitive land plants? One possibility is that the most ancient role of KANADI and HDZIPIII proteins was to regulate growth in response to environmental cues. A rich environment would result in high HD-ZIPIII levels/low KANADI levels with consequent growth, whereas a poor environment would result in high KANADI levels/low HD-ZIPIII levels with consequent growth arrest. In support of this, the regulatory link between HD-ZIPIII and KANADI, and genes involved in ABA signaling may be ancient (E Magnani et al., unpubl.). In higher plants, HD-ZIPIII and KANADI activities may have evolved to come under tissue specific controls, thus patterning growth within the plant. Given recent progress in making the basal plants Marchantia (a liverwort) and Physcomitrella (a moss) into model organisms, it should be straight forward to determine the function of HD-ZIPIII and KANADI functions in non vascular land plants.

It is clear from our work on Arabidopsis that many tens if not hundreds of genes have evolved to become transcriptional targets of REVOLUTA and KANADI proteins. It is likely that the set of genes targeted by these factors will vary among species and include both a conserved, core set of ancient targets as well as a more variable and recently evolved set of targets. Defining these target sets across species should provide important information on how regulatory circuits evolve and also prove useful in understanding the broad diversity of leaf form and cellular specializations among plants.

\section{ACKNOWLEDGMENTS}

This work was supported by grant number GM06929 from the National Institutes of Health and grants 09929413 and 0721852 from the National Science Foundation.

\section{REFERENCES}

Bhattacharya D, Medlin L. 1998. Algal phylogeny and the origin of land plants. Plant Physiol 116: $9-15$.

Bonke M, Thitamadee S, Mähönen AP, Hauser M-T, Helariutta Y. 2003. APL regulates vascular tissue identity in Arabidopsis. Nature 426: 181-185.

Bou-Torrent J, Salla-Martret M, Brandt R, Musielak T, Palauqi JC, Martinez-Garcia JF, Wenkel S. 2012. ATHB4 and HAT3, two class II HD-ZIP transcription factors, control leaf development in Arabidopsis. Plant Signal Behav 7: $1382-1387$.

Brandt R, Salla-Martret M, Bou-Torrent J, Musielak T, Stahl M, Lanz C, Ott F, Schmid M, Greb T, Schwarz M, et al. 2012. Genome-wide binding-site analysis of REVOLUTA reveals a link between leaf patterning and light-mediated growth responses. Plant J 72: 31-42.

Causier B, Ashworth M, Guo W, Davies B. 2012. The TOPLESS interactome, framework for gene repression in Arabidopsis. Plant Physiol 158: $423-438$.

Chandler JW, Cole M, Flier A, Grewe B, Werr W. 2007. The AP2 transcription factors DORNROSCHEN and DORNROSCHEN-LIKE redundantly control embryo patterning via interaction with PHAVOLUTA. Development 134: 16531662.

Cheng Y, Qin G, Dai X, Zhao Y. 2007. NPY1, a BTB-NPH3-like protein, plays a critical role in auxin-regulated organogenesis in Arabidopsis. Proc Natl Acad Sci 104: 18825-18829.

Cheng Y, Qin G, Dai X, Zhao Y. 2008. NPY genes and AGC kinase genes define two key steps in auxin-mediated cotyledon organogenesis. Proc Natl Acad Sci 105: 21017-21022.

Ciarabelli M, Sessa G, Baima S, Morelli G, Ruberti I. 1993. The Arabidopsis Athb-2 and -4 genes are strongly induced by farred-rich light. Plant J 4: 469-479.

Dhonukshe P, Huang F, Galvan-Ampudia CS, Mähönen AP, Kleine-Vehn J, Xu J, Quint A, Prasad K, Friml J, Scheres B, et al. 2010. Plasma membrane-bound AGC3 kinases phosphorylate PIN auxin carriers at TPRXSN/S motifs to direct apical PIN recycling. Development 137: 3245-3255.

Emery JF, Floyd SK, Alvarez J, Eshed Y, Hawker NP, Izhaki A, Baum SF, Bowman JL. 2003. Radial patterning of Arabidopsis shoots by Class III HD-ZIP and KANADI genes. Curr Biol 13: $1768-1774$.

Eshed Y, Baum S, Bowman J. 1999. Distinct mechanisms promote polarity establishment in carpels of Arabidopsis. Cell 99: 199-209.

Eshed Y, Baum SF, Perea JV, Bowman JL. 2001. Establishment of polarity in lateral organs of plants. Curr Biol 11: 1251-1260.

Eshed Y, Izhaki A, Baum SF, Floyd SK, Bowman JL. 2004. Asymmetric leaf development and blade expansion in Arabidopsis are mediated by KANADI and YABBY activities. Development 131: 2997-3006.

Etchells JP, Turner SR. 2010. The PXY-CLE41 receptor ligand pair defines a multifunctional pathway that controls the rate and orientation of vascular cell division. Development 137: 767-774.

Evans MM. 2007. The indeterminate gametophytel gene of maize encodes a $\mathrm{LOB}$ domain protein required for embyo sac and leaf development. Plant Cell 19: 46-62.

Floyd SK, Zalewski CS, Bowman JL. 2006. Evolution of class III homeodomain-leucine zipper genes in streptophytes. Genetics 173: 373-388.

Furutani M, Kajiwara T, Kato T, Treml B, Stockum C, TorresRuiz R, Tasaka M. 2007. The gene MACCHI-BOU4/ 
ENHANCER OF PINOID encodes a NPH3-like protein and reveals similarities between organogenesis and phototropism at the molecular level. Development 134: 3849-3859.

Furutani M, Sakamoto N, Yoshida S, Kajiwara T, Robert HS, Friml J, Tasaka M. 2011. Polar-localized NPH3-like proteins regulate polarity and endocytosis of PIN-FORMED auxin efflux carriers. Development 138: 2069-2078.

Grigg SP, Galinha C, Kornet N, Canales C, Scheres B, Tsiantis M. 2009. Repression of apical homeobox genes is required for embryonic root development in Arabidopsis. Curr Biol 19: $1485-1490$.

Guo J, Yang X, Weston DJ, Chen J-G. 2011. Abscisic acid receptors: Past, present and future. J Integr Plant Biol 53: 469-479.

Heisler MG, Ohno C, Das P, Sieber P, Reddy GV, Long JA, Meyerowitz EM. 2005. Patterns of auxin transport and gene expression during primordium development revealed by live imaging of the Arabidopsis inflorescence meristem. Curr Biol 15: 1899-1911.

Hosoda K, Imamura A, Katoh E, Hatta T, Tachiki M, Yamada H, Mizuno T, Yamazaki T. 2002. Molecular structure of the GARP family of plant Myb-related DNA binding motifs of the Arabidopsis response regulators. Plant Cell 14: 2015-2029.

Husbands A, Chitwood DH, Plavskin Y, Timmermans MC. 2009. Signals and prepatterns: New insights into organ polarity in plants. Genes Dev 23: 1986-1997.

Ioio RD, Galinha C, Fletcher AG, Grigg SP, Molnar A, Willhemsen V, Scheres B, Sabatina S, Baulcombe D, Maini PK, et al. 2012. PHABULOSA cytokinin feedback loop controls root growth in Arabidopsis. Curr Biol 22: 1699-1704.

Izhaki A, Bowman JL. 2007. KANADI and class III HD-ZIP gene families regulate embryo patterning and modulate auxin flow during embryogenesis in Arabidopsis. Plant Cell 19: 495-508.

Jönsson H, Heisler MG, Shapiro BE, Meyerowitz EM, Mjolsness E. 2006. An auxin-driven polarized transport model for phyllotaxis. Proc Natl Acad Sci 103: 1633-1638.

Kelley DR, Skinner DJ, Gasser CS. 2009. Roles of polarity determinants in ovule development. Plant J 57: 1054-1064.

Kelley DR, Arreola A, Gallagher TL, Gasser CS. 2012. ETTIN ARF3 physically interacts with KANADI proteins to form a functional complex essential for integument development and polarity determination in Arabidopsis. Development 139: $1105-1109$.

Kerstetter RA, Laudencia-Chingcuanco D, Smith LG, Hake S. 1997. Loss-of-function mutations in the maize homeobox gene, knottedl are defective in shoot meristem maintenance. Development 124: 3045-3054.

Kerstetter RA, Bollman K, Taylor RA, Bomblies K, Poethig RS. 2001. KANADI regulates organ polarity in Arabidopsis. $\mathrm{Na}$ ture 411: 706-709.

Kim YS, Kim SG, Lee M, Lee I, Park HY, Seo PJ, Jung JH, Kwon EJ, Suh SW, Paek KH, et al. 2008. HD-ZIP III activity is modulated by competitive inhibitors via a feedback loop in Arabidopsis shoot apical meristem development. Plant Cell 20: $920-933$.

Leon-Kloosterziel KM, Keijzer CJ, Koornneef M. 1994. A seed shape mutant of Arabidopsis that is affected in integument development. Plant Cell 6: 385-392.

Liu C, Xu Z, Chua NH. 1993. Auxin polar transport is essential for the establishment of bilateral symmetry during early plant embryogenesis. Plant Cell 5: 621-630.

Long J, Barton MK. 2000. Initiation of axillary and floral meristems in Arabidopsis. Dev Biol 218: 341-353.

Long JA, Moan EI, Medford JI, Barton MK. 1996. A member of the KNOTTED class of homeodomain proteins encoded by the STM gene of Arabidopsis. Nature 379: 66-69.

Lynn K, Aida M, Sedbrook J, Masson P, Tasaka M, Barton MK. 1999. The PINHEAD/ZWILLE gene acts pleiotropically in Arabidopsis development and has overlapping functions with the ARGONAUTE 1 gene. Development 126: 469-481.

Magnani E, Barton MK. 2011. A per-ARNT-sim-like sensor domain uniquely regulates the activity of the homeodomain leucine zipper transcription factor REVOLUTA in Arabidopsis. Plant Cell 23: 567-582.
Mallory AC, Reinhart BJ, Jones-Rhoades MW, Tang G, Zamore PD, Barton MK, Bartel DP. 2004. MicroRNA control of PHABULOSA in leaf development: Importance of pairing to the microRNA 5' region. EMBO J 23: 2256-3364.

McAbee JM, Hill TA, Skinner DJ, Izhaki A, Hauser BA, Meister RJ, Reddy GV, Meyerowitz EM, Bowman JL, Gasser CS. 2006. ABERRANT TESTA SHAPE encodes a KANADI family member, linking polarity determination to separation and growth of Arabidopsis ovule integuments. Plant J 46: $522-531$.

McConnell JR, Barton MK. 1998. Leaf polarity and meristem formation in Arabidopsis. Development 125: 2935-2942.

McConnell JR, Emery J, Eshed Y, Bao N, Bowman J, Barton MK. 2001. Role of PHABULOSA and PHAVOLUTA in determining radial patterning in shoots. Nature 411: 709-713.

Möller B, Weijers D. 2009. Auxin control of embryo patterning. Cold Spring Harb Perspect Biol 1: a001545.

Mukherjee K, Brocchieri L, Burglin TR. 2009. A comprehensive classification and evolutionary analysis of plant homeobox genes. Mol Biol Evol 26: 2775-2794.

Navarro L, Dunoyer P, Jay F, Arnold B, Dharmasiri N, Estelle M, Voinnet O, Jones JD. 2006. A plant miRNA contributes to antibacterial resistance by repressing auxin signaling. Science 312: $436-439$.

Ochando I, Jover-Gil S, Ripoll JJ, Candela H, Vera A, Ponce MR, Martinez-Laborda A, Micol JL. 2006. Mutations in the microRNA complementarity site of the INCURVATA4 gene perturb meristem function and adaxialize lateral organs in Arabidopsis. Plant Physiol 141: 607-619.

Park S-Y, Fung P, Nishimura N, Jensen DR, Fujii H, Zhao Y, Lumba S, Santiago J, Rodrigues A, Chow TF, et al. 2009. Abscisic acid inhibits type $2 \mathrm{C}$ protein phosphatases via the PYR/ PYL family of START proteins. Science 324: 1068-1071.

Pekker I, Alvarez JP, Eshed Y. 2005. Auxin response factors mediate Arabidopsis organ asymmetry via modulation of KANADI activity. Plant Cell 17: 61-76.

Ploense SE, Wu MF, Nagpal P, Reed JW. 2009. A gain of function mutation in IAA18 alters Arabidopsis embryonic apical patterning. Development 136: 1509-1517.

Prigge MJ, Otsuga D, Alonso JM, Ecker JR, Drews GN, Clark SE. 2005. Class III homeodomain-leucine zipper gene family members have overlapping, antagonistic, and distinct roles in Arabidopsis development. Plant Cell 17: 61-76.

Reinhardt D, Mandel T, Kuhlemeier C. 2000. Auxin regulates the initiation and radial position of plant lateral organs. Plant Cell 12: 507-518.

Reinhardt D, Pesce ER, Stieger P, Mandel T, Baltensperger K, Bennett M, Traas J, Frim J, Kuhlemeier C. 2003. Regulation of phyllotaxis by polar auxin transport. Nature 426: 255-260.

Sessa G, Steindler C, Morelli G, Ruberti I. 1998. The Arabidopsis Athb-8, -9 and -14 genes are members of a small gene family coding for highly related HD-ZIP proteins. Plant $\mathrm{Mol}$ Biol 38: 609-622.

Sinha NR, Williams RE, Hake S. 1993. Overexpression of the maize homeo box gene, KNOTTED-1, causes a switch from determinate to indeterminate cell fates. Genes Dev 7: 787795.

Smith ZR, Long JA. 2010. Control of Arabidopsis apical-basal embryo polarity by antagonistic transcription factors. Nature 464: $423-426$.

Spalding EP. 2013. Diverting the downhill flow of auxin to steer growth during tropisms. Am J Bot 100: 203-214.

Stepanova AN, Robertson-Hoyt J, Yun J, Benavente LM, Xie DY, Dolezal K, Schlereth A, Jürgans G, Alonso JM. 2008. TAA1-mediated auxin biosynthesis is essential for hormone crosstalk and plant development. Cell 133: 177-191.

Talbert PB, Adler HT, Parks DW, Comai L. 1995. The REVOLUTA gene is necessary for apical meristem development and for limiting cell divisions in the leaves and stems of Arabidopsis thaliana. Development 121: 2723-2735.

Waites R, Hudson A. 1995. Phantastica: A gene required for dorsiventrality of leaves in Antirrhinum majus. Development 121: $2143-2154$. 


\section{OF BLADES AND BRANCHES}

Welch D, Hassan H, Blilou I, Immink R, Heidstra R, Scheres B. 2007. Arabidopsis JACKDAW and MAGPIE zinc finger proteins delimit asymmetric cell division and stabilize tissue boundaries by restricting SHORT ROOT action. Genes Dev 21: 2196-2204.

Wenkel S, Emery J, Hou BH, Evans MMS, Barton MK. 2007. A feedback regulatory module 2007 formed by LITTLE ZIPPER and HD-ZIPIII genes. Plant Cell 19: 3379-3390.

Wu G, Lin WC, Huang T, Poethig RS, Springer PS, Kerstetter RA. 2008. KANADI1 regulates adaxial-abaxial polarity in
Arabidopsis by directly repressing the transcription of ASYMMETRIC LEAVES2. Proc Natl Acad Sci 105: 16392-16397.

Wykoff DD, Growwman AR, Weeks DP, Usuda H, Shimogawar K. 1999. Psr1, a nuclear localized protein that regulates phosphorus metabolism in Chlamydomonas. Proc Natl Acad Sci 96: $15336-15341$

Zhu H, Hu F, Wang R, Zhou X, Sze S-H, Liou LW, Barefoot A, Dickman M, Zhang X. 2011. Arabidopsis Argonaute10 specifically sequesters miR166/165 to regulate shoot apical meristem. Dev Cell 145: 242-256. 


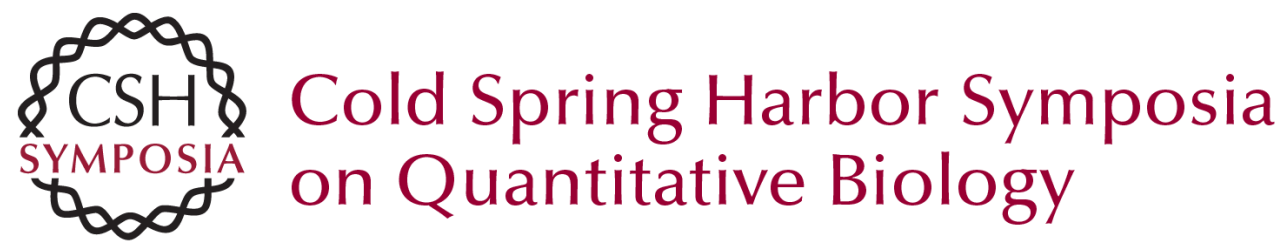

\section{Of Blades and Branches: Understanding and Expanding the Arabidopsis Ad/Abaxial Regulatory Network through Target Gene Identification}

T. Liu, B.J. Reinhart, E. Magnani, et al.

Cold Spring Harb Symp Quant Biol 2012 77: 31-45 originally published online May 7, 2013 Access the most recent version at doi:10.1101/sqb.2013.77.014480

References This article cites 64 articles, 40 of which can be accessed free at: http://symposium.cshlp.org/content/77/31.full.html\#ref-list-1

\section{License}

Email Alerting Receive free email alerts when new articles cite this article - sign up in Service the box at the top right corner of the article or click here. 